\title{
De muertas y policías. La duplicidad de la novela negra en la obra de Roberto Bolaño
}

NILIA UISGARDI

\section{Resumen}

Se presenta una sociología de las representaciones de la violencia a partir del estudio de la novela policial. Tomando como base los comentarios frankfurtianos sobre el auge de la novela policial en la modernidad, se comparan dos escritores europeos (Andrea Camilleri y Henning Mankell) con un latinoamericano (Roberto Bolaño). 2666, la novela de Bolaño, se construye desde un tipo particular de violencia social relacionada con la impunidad y la impotencia del estado, o en definitiva, con la imposibilidad del proyecto moderno. Esta realidad da lugar a un tipo de representación que se aparta de los cánones de la novela policial, como se apreciará en la caracterización del detective. Investigando los violentos desafíos al frágil orden social, este nuevo tipo de novela policial latinoamericana pone en cuestión los mecanismos de representación de la muerte, esto es, la representación de lo irrepresentable.

Palabras-clave: Representaciones de la violencia. Roberto Bolaño. Literatura y violencia. Novela policial.

\footnotetext{
"Universidad de la Republica, Montevideo, Uruguay.
} 


\section{On dead women and policemen. The duplicity of the crime fiction in the work of Roberto Bolaño}

\section{Abstract}

The article presents a sociological analysis of violence representations based on the study of crime fiction. Relying on the Frankfurtian comments on the booming of crime fiction in the modernity, two European writers (Andrea Camilleri and Henning Mankell) are compared with a Latin American one (Roberto Bolaño). Bolaño's novel, 2666, is built on a particular kind of social violence related to both impunity and the State incompetence or, ultimately, to the non-feasibility of the Modern Project. Such reality creates room for a kind of representation that strays from the canons of crime fiction, as it will be noticed in the characterization of the detective. Inquiring into the violent challenges to the flimsy social order, this new kind of Latin American detective fiction calls into question the representations of death, that is, the representation of what cannot be represented.

Keywords: Representations of violence. Noir fiction. Roberto Bolaño. Literature and violence.

\section{Introducción}

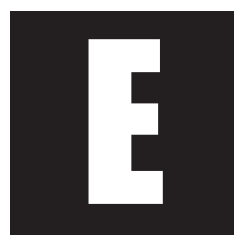

I libro 2666 es una novela póstuma del escritor chileno Roberto Bolaño (1953-2003) publicada en el año 2004. Consta de cinco partes pensadas originalmente como cinco libros independientes. Gran parte de la acción transcurre en la ciudad ficticia de Santa Teresa, que se ha identificado con Ciudad Juárez. De los cinco capítulos, La parte de los muertos constituye el eje conductor de toda la novela por vía de los feminicidios que tienen lugar en Santa Teresa. Comenzando por la aparición del cadáver de Esperanza Gómez Saldaña, Bolaño describe los asesinatos que se han cometido entre enero de 1993 y diciembre de 1997. 
Basándonos en esta obra, y específicamente en el estudio de La parte de los muertos procuraremos desvendar algunos de los hilos de la violencia contemporánea y de la mortalidad criminal en México, un país que presenta altos niveles de violencia social en la realidad latinoamericana. Caracterizando a grandes rasgos esta trama, intentaremos mostrar el poder de la obra literaria y del estilo elegido por Bolaño como forma expresiva que contribuye a la comprensión de la violencia social. Con ello, intentamos buscar alternativas para enfrentar algunos límites que las dinámicas de la violencia homicida y sus representaciones imponen al trabajo sociológico y frente a las cuales la literatura guarda mayor poder en tanto herramienta de comprensión de sus expresiones culturales y humanas.

El problema de representar la muerte y sus dinámicas subyace a toda sociedad. En nuestro mundo contemporáneo, la violencia criminal y delictiva testimonia de una sociabilidad dilacerada, de una solidaridad quebrada, que se expresa en la existencia de formas crueles e inhumanas de homicidio y apartamiento de la vida. Una de las formas sociales de representar, enunciar y, por qué no, exorcizar esta dinámica de la violencia social contemporánea la constituye la literatura por vía de la novela policial y de la novela negra.

Buscamos en la novela negra herramientas que nos permitan describir características expresivas de la violencia urbana actual de modo de captar la singularidad histórica que tiene el homicidio y sus manifestaciones en nuestras culturas. Parte de estas características expresivas refieren a las formas de la muerte violenta (los feminicidios en este caso), parte a sus ritualidades y efectos en un territorio y parte a sus consecuencias en un determinado orden social (moralidad y justicia). Abordamos por tanto las dinámicas sociales del procesamiento de la muerte y sus manifestaciones en la trama narrativa que la novela negra ofrece: surgen en ella elementos de abordaje de lo innombrable, que el recurso literario permite enunciar con mayor potencia. 


\section{Novela Negra y conflicto social}

Desde la obra de la escuela de Frankfurt, se ha aceptado que la producción artística y cultural puede ser empleada como material de estudio a partir del cual los analistas pueden examinar tendencias de época, lógicas culturales y procesos colectivas que se manifiestan. A ello podemos abocarnos con el análisis del texto artístico y literario.

Por "novela negra" se denomina el estilo aplicado a un subgénero narrativo relacionado con la novela policial y que surge en Norteamérica a comienzos de los años veinte. En él, sus autores tratan de reflejar, desde una conciencia crítica, el mundo del gangsterismo y de la criminalidad organizada, producto de la violencia y corrupción de la sociedad capitalista de esa época (Estébanez Calderón, 1996). Los relatos siguen básicamente el esquema de la novela policial que consiste en la presencia de un crimen, investigación del mismo por un detective, descubrimiento y persecución de los culpables. Asimismo se suele señalar una organización similar en el desarrollo de la historia. Las diferencias, no obstante, se centran en que:

el interés primordial no radica tanto en la resolución del problema como en la configuración de un cuadro de conflictos humanos y sociales, además de un estudio de caracteres, a partir de un enfoque realista y sociopolítico de la contemporánea temática del crimen (Estébanez Calderón, 1996, p. 760). ${ }^{1}$

Tomaremos como recurso de interpretación el trabajo de Kracauer (2011) sobre la novela policial, obra que se inscribe en la corriente de las reflexiones que, sobre el arte y la modernidad, ha desarrollado la Escuela de Frankfurt. Situado en el análisis específico de la novela policial,

\footnotetext{
${ }^{1}$ El autor destaca además el indudable prestigio literario cobrado por la novela negra a diferencia de la novela policial que muchas veces Ha sido tachada de "paraliteratura" (Estébanez Calderón, 1996).
} 
sus aportes brindan claves de reflexión para interpretar lo que, en cierto orden de representaciones, aún brindaba esta forma literaria para comprender la violencia de las sociedades modernas. Aunque la novela negra no es novela policial, es en las distinciones respecto de aquel estilo que podremos situar algunas especificidades del trabajo de Bolaño. En determinadas instancias, recurriremos a la comparación, estableciendo algunos contrapuntos con el trabajo de Andrea Camilleri (Italia) y Henning Mankell (Suecia) de modo de situar la especificidad de la mirada a la violencia criminal y homicida relatada por Bolaño en México. El estilo en que se produce el giro de la novela policial a la novela negra obedece, también, a escenarios sociales diversos en que acontecen delitos y homicidios. De allí que, en la producción europea referida, aún persista la figura del detective policía como guía narrativo.

En relación a la justicia, la distancia que la novela tiene respecto de un proceso de investigación criminal o judicial típico - en tanto no configura efectos de realidad en el proceso que narra - permite mostrar las lógicas, prácticas y sentidos de la acción que se esconden atrás del proceso que busca dar cuenta del porqué, cómo y quiénes han matado y de las dinámicas de poder, saber y verdad que se establecen (Foucault, 2006) ${ }^{2}$. En toda sociedad, este es un proceso históricamente pautado cuyas reglas han de seguirse para reparar el daño causado por un exceso de poder (Tavares de Santos, 2009) sobre una persona o grupo social. De este modo, es que trabajaremos una narración en que individuos vencidos y que procuran encontrar "la verdad" (o alguna al menos) despliegan su búsqueda

\footnotetext{
${ }^{2}$ Esto contribuye al estudio de los mecanismos mediante los cuales las sociedades tienen diversas estrategias generales de poder en contexto de una sociología de las tecnologías de seguridad o proyecto de análisis de la gubernamentalidad. Se trata de abordar formas de experiencia y racionalidad a partir de las cuales se organiza el poder sobre la vida en occidente y de las cuales el proceso policial y judicial forman parte en las dinámicas de la violencia y la criminalidad contemporáneas.
} 
en escenarios unidos por la mortalidad violenta y las dinámicas sociales e institucionales que personifican la prensa, la justicia y la policía.

En la novela negra, la imposibilidad de resolver el misterio es mucho más un pretexto para mostrar la crueldad del mundo contemporáneo, que un objetivo final de la obra. Con límites borrosos entre el bien y el mal, la búsqueda inacabada de la verdad que pauta la novela negra permite recrear los trazos que, en la escuela de Frankfurt, se vinculaban al poder liberador de la obra de arte, a la vez que profundizan la mirada crítica sobre un mundo sin salidas. Sin establecerla como obra de arte, Kracauer sostiene que la novela policial aún contribuye:

a la operación mínima de la existencialidad artística: construir a partir de los elementos de un mundo desarticulado, elementos dispersos que se mueven a ciegas, un todo que, aunque sólo refleje este mundo de manera aparente, lo capta en su totalidad y permite así la proyección de sus elementos a los hechos reales (Kracauer, 2010, p. 40).

Finalmente, para pensar y comprender la muerte y la violencia social en América Latina en tanto "cuadro de conflictos humanos y sociales" a través de la obra de Bolaño, 2666, nos basaremos en aquello que, al quedar incompleto en la novela negra a diferencia de la novela policial, radicaliza el valor literario del género y permite representar la violencia criminal de nuestro continente. Es esta contemporaneidad marcada por una violencia cruel y arbitraria la que está presente en el mundo de Bolaño tanto como en el de Camilleri o Mankell. Pero mientras, en Bolaño (2011), la violencia de las muertes ocurridas en 2666 parece unificar un conjunto de relatos que combinan rasgos de lo detectivesco y de poema épico, de novela de artista y de novela filosófica involucrando un conjunto de personajes unidos por la literatura, en Camilleri o Henning la búsqueda de la lógica que se encuentra tras la oscura realidad se despliega a través de los padecimientos del detective cuya vida cotidiana 
acompaña el desenlace en el tradicional escenario de las comisarías y su vida cotidiana.

Con estilos contrastantes, las violencias de la contemporaneidad estructurales, simbólicas y de la vida cotidiana (Bourgois, 2005) - acontecen en un mundo en que los orígenes sociales de la violencia se denuncian mostrando la impotencia de las tradicionales interpretaciones individuales del conflicto social presentes en la lógica de la novela policial. La anhelada "resolución del caso" en la novela moderna - el hallazgo del "psicópata" "enfermo" o "manipulador" - daba cuenta, en cierta medida, de un acto de justicia y reparación. Ejemplo de ello, como transición entre la novela policial y la novela negra, es la lucha de Salvo Montalbano en Camilleri: la impotencia del investigador que resuelve "el caso" se expresa en cada instancia al desnudar la imposibilidad de resolver el mundo y encontrar justicia más allá "del caso". Esta conciencia de la complejidad estructural de la violencia, confronta la utopía de la justicia a la realidad de una sociedad desintegrada, disminuyendo el poder de la ley frente a las fuerzas sociales desatadas en una contemporaneidad fragmentada.

Buscando recursos estilísticos alternativos, en la novela negra, el atractivo que la búsqueda de la verdad - una verdad desesperanzada ahora - producía en la lógica deductivo-inductiva propia del romance policial a principios del siglo XX cambia sus formas. No hay modo de encontrar el bien y el mal (una clase social, un grupo dominante, una fracción de la sociedad) en estado puro, ni de encarnarlos en un personaje. Se desvenda la aleatoriedad del mundo, aleatoriedad que expresa el desamparo humano ante la crueldad y la violencia de una sociedad carente de utopías, luchas políticas y justicia social.

Esta búsqueda imposible (saber para reparar el daño social: saber la verdad) que aleja la novela negra puede entenderse como acto político. La imposibilidad de representar la justicia es la denuncia de un ideal que- 
brado - de un acto de barbarie - y se objetiva en la dificultad de realizar la operación interpretativa (la reconstrucción del caso). Si - como lo establece Jameson - la historia es la que deriva de las nociones y categorías que pone en juego un determinado código hermenéutico como constructo teórico, la lectura y organización de los acontecimientos cronológicos en una narración están focalizados por la ideología. El resultado es el establecimiento de visiones del mundo:

esa designación intraducible en la que los problemas actuales de la 'representación' se cruzan productivamente con aquellos bastante diferentes de la 'presentación', o del movimiento esencialmente narrativo o retórico del lenguaje y de la escritura a lo largo del tiempo (Jameson, 1989, p. 14).

Para abordar estas visiones del mundo que se instalan en una contemporaneidad surcada por la violencia urbana homicida, retrataremos algunos rasgos de la violencia social contemporánea.

\section{Violencia y muerte: desafíos al pensamiento sociológico}

La muerte es, más que el sexo, el tema tabú de nuestra sociedad occidental (Foucault, 1976). Finalizada la era en que la muerte estaba siempre presente y era familiar, ella se ha convertido en lo innominable (Ariès, 1982). La muerte de que nos ocupamos aquí, aquella que resulta de la criminalidad o la violencia sexual, resulta aún más interpelante en tanto la novela desvenda una trama que no se resuelve en la novela negra. Y se presenta bajo modalidades que desafían las formas aceptadas de morir, a solas o en el hospital. Escapando a sus causas "normales", estas muertes reavivan los miedos de época en tanto atestiguan que la barbarie y la violencia, aquello que el proceso civilizatorio debió hacer retroceder (Elías, 1939), siguen vigentes. 
La novela negra despliega los escenarios de la violencia social contemporánea escenificando la violencia doméstica, interpersonal y delictiva y entrando en la infinita trama de la "violencia urbana", de la "criminalidad violenta" y de la "violencia homicida". Permite así una aproximación a su lógica cultural en tanto fenómeno propio del capitalismo tardío Para la sociología, todas ellas son, como lo establece Misse (2012), nociones que se impregnan de tal modo de representaciones sociales estereotipadas, que dejan muchas veces la impresión de un connubio insensato entre las dimensiones ideológicas del objeto y su construcción conceptual, generalizando una "sociología moralizante". La novela, y particularmente la novela negra, paradójicamente nos permite un acercamiento que brinda otras claves de comprensión de las diferentes formas de violencia urbana, criminal y homicida en tanto ya se mueve en el escenario de las formas violentas del crimen, de la ruptura de un ideal humanista y del conflicto social en sus expresiones difusas y apolíticas.

En la matriz del pensamiento sociológico, el problema de la violencia fue situado como interpelante del orden, un orden moral que al ser violentado imponía sanciones. Cuando Durkheim (1988) se propone definir el hecho social, establece que en toda sociedad hay un determinado grupo de fenómenos que se distinguen por caracteres precisos, que se expresan en modos de obrar, de pensar y de sentir, que existen fuera de las conciencias individuales. Los fenómenos a los que aludirá para referir a la integración de estos modos de obrar y pensar lo hacen hablar de la educación: el hecho social deviene en una sociología de los sentimientos y las moralidades. Los fenómenos que, de modo negativo, ponen a luz la fuerza de la sociedad para imponerse sobre las conciencias refieren a la transgresión del orden social, la violación de las normas y la violencia. No obstante, no les confiere una naturaleza ontológica, sino que su naturaleza es variable y depende del grado de desarrollo de cada sociedad tanto 
en lo que refiere a lo que se considera violento como a las modalidades históricas que toman la ley y el castigo.

Hoy, el problema de la violencia y de la integración continúa en el centro de la sociología, poniendo en juego la articulación entre individuo y sociedad y buscando en el "ideal de sociedad integrada" un objeto que no supera - a nivel histórico - el orden del imaginario. Esto es lo que descentra el giro de la novela policial a la novela negra: no se cree en la posibilidad de la "integración", sino que se vive el escenario de la fragmentación (social, cultural, económica). La riqueza aparece en el potencial de las configuraciones narrativas que muestran visiones del mundo en las presentaciones que se hacen. El modo en que Bolaño relata las muertes permite una mirada cabal a nuestros actuales modelos de dominación social y de construcción de legitimidad que supera la aparente fragmentación del relato al mostrar las formas asociativas de la violencia institucional (el Estado, la policía, la justicia), de la violencia estructural (economía, cultura y política), de la violencia cotidiana (violencia doméstica y de género) y simbólica (prensa y figuras culturales). Todas ellas se articulan tras la aparente lógica fragmentada de la novela y de La parte de las muertes siguiendo la cotidianeidad noticiosa que se vive, que denuncia la biopolítica que se ejerce en un territorio y se manifiesta en la nuda vida.

Y estos modos de dominación, de ejercicio legítimo de la fuerza y de la violencia en cada orden, así como de las formas de mortalidad aceptadas, también requieren de rituales y expresiones simbólicas que poco conocemos. En cada orden social, la separación entre vivos y muertos es resultante de un proceso para el cual distintas sociedades han encontrado diferentes modos de resolución. El tipo de muerte, de hecho, determina tanto las reacciones ante ella como el tipo de rituales que se desarrollarán (Pita, 2010). La novela negra tiene la virtud de mostrar y desplegar diversos escenarios - los que Bolaño nos propone para México, por ejemplo 
- en que la muerte determina la exclusión de la vida de aquellos que estaban destinados a ella o de aquellos a quienes la sociedad entiende que debe proteger: mujeres y mujeres jóvenes particularmente.

Ahora, este acto de exclusión de la vida que se sale de lo "normal", ¿puede reducirse, en la narración, al esclarecimiento de lo que ha producido un "desvío"? Ello nos induce a la tradicional "anomalía" en el pensamiento Durkheimiano y en gran parte de la sociología moderna. Estas "anomias", estos problemas de funcionamiento, irían a corregirse con el avance de la modernidad, el retroceso de la desigualdad, el progreso de la historia, de la ciencia y el avance de los derechos individuales y sociales. El homicidio cruento, las muertes accidentales, la desprotección de los más débiles, el apartamiento del mundo de los vivos por el suicidio, no podían ser pensados fuera de la idea de anomia.

Paulatinamente, las diversas corrientes de ideas fueron incorporando la idea de una modernidad desarrollada sin progreso o mejora de la condición humana, permitiendo de este modo superar la noción de anomia social. El hecho social también produce, con normalidad, un conjunto de comportamientos que pueden expresar "desvío" (Merton, 1969; Becker, 1966) en cierto paradigma; fracaso del modelo de "normalización" (Foucault, 1979) o del proceso civilizatorio que conduce al "autocontrol" (Elías, 1939) en otras visiones. Claro es que el asesinato resultante de una acción que tiene por móvil el lucro o que ocurre luego de una violación tienen otro estatus y evaluación social que los delitos que suponen el hurto, la rapiña o los delitos de cuello blanco.

El problema de la normalidad en contexto de aumento de violencias mortales protagonizadas en América Latina nos alejó definitivamente del marco que Durkheim establecía, sin por ello negar la importancia de la pregunta respecto del tipo de hecho social de que se trata. Al decir de Misse, cuando una violencia que se define por su individualización insó- 
lita comienza a alcanzar una regularidad y un alcance social ampliado, el concepto de desvío es imposible de utilizar pues su acumulación social le retira cualquier singularidad e, incluso siendo un curso de acción cuantitativamente minoritario, produce un nuevo estatuto cuyos efectos no pueden aislarse pensándolos desde categorías jurídicas. La peligrosidad, como concepto, y el riesgo, retoman su estatuto para explicar el punto en que determinadas violencias son intolerables.

Un riesgo es más intolerable no en función de su mayor probabilidad, sino en virtud de haber sido causado por otro humano, de tener un responsable identificado, que puede haber actuado adrede y haber obtenido beneficios, todos factores que lo vuelven más condenable - en la medida que era evitable $-y$, por ende, motivo tanto de ira como preocupación (Kessler, 2009, p. 63).

Precariedad, trabajo informal y explotación, prostitución, drogas, calle y falta de vivienda son parte del escenario social que caracteriza el lugar destinado a amplios conjuntos de la población. Es en este contexto que se desarrollan la naturalización y acumulación de una violencia social, se hace la emergencia de líneas de acción que operan contradictoriamente una valorización personal del empleo o amenaza de empleo del uso de la fuerza (y de sus extensiones tecnológicas) a la vez que, en un movimiento análogo, la fuerza de la ley establece su poder de definición de la situación (Misse, 2012). En este marco, la norma y la ley no desaparecen, de lo cual se deriva la posibilidad de la sujeción criminal y la sanción penal. Pero los individuos valorizan el riesgo y se incluyen irracionalidades pasionales en su curso de acción. Así, la reproducción social de individuos incontenidos y excesivos, cuyos comportamientos no se encuentran ya contenidos por las estrategias normalizadoras, hace que, en este modelo social, no puedan ser pensados como "anómalos" o "desviantes". 
Dado que ese proceso es socialmente fragmentado y fuertemente individualizado, se desarrolla una reciprocidad negativa, basada en cálculos de relación de fuerza, pero también se descontrola la posibilidad del cálculo a través de la emergencia de irracionalidades pasionales (rabia, odio, ira, envidia, crueldad, pasiones, etc.) anteriormente contenidas por estrategias normalizadoras del interés privado. Aparece así un individuo incontenido, excesivo, destructivo de sí mismo y de los otros, incluso para su propia auto representación; la reproducción social de ese individuo lo aparta del confinamiento individualizador de la ideología jurídica o de las nociones sociológicas de comportamiento desviante, divergente o problemático. Un individuo que sustituye (o somete) la referencia de la norma por la referencia al riesgo, al destino o a la elección. Pero mientras la norma sometida o sustituida continúe siendo hegemónica, será pasible de sujeción criminal (Misse, 2012, p. 35).

Resultante de la instalación de un modelo social excluyente que acentúa una realidad de pobreza y desigualdad, la materialidad de la diferenciación se verifica en la presencia de experiencias sociales diferentes y socialmente distantes (Le Blanc, 2007). Los casos de homicidios relatados en Bolaño denuncian subjetividades marcadas por la experiencia estructural de la impunidad, la distancia con la Ley, el individualismo negativo, las pasionalidades irracionales, el lucro y la explotación como cursos regulares de la acción social. El poder de la novela está en desplegar estas prácticas, mostrar las subjetividades y realidades en juego. Este universo, en la investigación sociológica, aún es difícil de abordar y de introducir en el juego de las investigaciones que existen en la práctica.

Como ya lo señalaba Becker, referencia en trabajos comprensivos y padre de la sociología del "desvío", el trabajo con personas y organizaciones vinculadas a actividades "desviantes" requiere del desarrollo de métodos nuevos, apropiados para el secreto que nos confronta, pues estas personas no suelen poner a disposición sus nombres en catálogos telefónicos (Becker, 
1997, p. 13). El análisis de las representaciones que la novela pone en juego, en este sentido, contribuye al ejercicio de comprensión (verstehen) sin el cual la explicación es imposible en ciencias sociales (Weber, 1992).

Pero la comprensión de los fenómenos de violencia criminal, la explicación de sus conexiones causales y relaciones sociales, mal se logra aún desde la racionalidad sociológica. Es que la operación de contraste con la realidad empírica, el pasaje por el "campo", constituye un desafío difícil de abordar desde el sistema de reglas y relaciones del campo científico. El arte, en este caso manifiesto en la novela negra (aunque la Escuela de Frankfurt no considere a este género como tal), muestra las potencialidades de la literatura - "el poder de la obra de arte" - como instrumento esclarecedor frente a las armas aún frágiles de la racionalidad y la práctica sociológica para abordar el problema de la violencia criminal, la muerte y el homicidio.

Pues, en el actual estadio de desarrollo de la sociología, aún se requiere de un acercamiento "material" al "campo": dando la palabra y conociendo a las personas, acercándose a la atrocidad de las prácticas y a la multiplicidad y continuidad de sus violencias y excesos. Y este acercamiento es, aún, un campo incipiente plagado de dudas. Estas constituyen dificultades de método que se suman al ideal de una ciencia que buscó en la sociología de la criminalidad respuestas a una integración que se postulaba como fin del proceso civilizatorio.

Mientras tanto, el relato de Bolaño (2011) de cuenta de todo tipo de experiencias de individualismo excesivo o egoísta (Misse, 2012) y de los tipos de sociabilidad emergentes. En América Latina - como lo establece Misse - este individualismo está claramente vinculado a las tensiones que el mercado introdujo en las formas de sociabilidad e integración social modernas. Si los dos signos centrales de la dinámica normalizadora de la modernidad fueron el sexo y el trabajo, veremos que la mayoría de las situaciones 
que se desarrollan en la ciudad de Sonora que nos relata Bolaño refieren, fundamentalmente, a emergentes vinculados a estas dimensiones.

Las violencias homicidas de Bolaño son, en algunos casos, violencias expresivas y en otros instrumentales. En algunos, mezcla de ambas. Cuando se trata de violencias expresivas, sin dudas, son sentimientos tales como la provocación, la ira o la "falta de respeto" los que pueden detonar la agresión. En estos escenarios carentes de "honor social" (Weber, 1992) apremia la necesidad de sentir respeto. La falta de respeto, a su vez, cuando evidente pone en juego de modo abierto la violencia de las distancias sociales.

IL Jos adolescentes del gueto son muy sensibles al hecho de que no se los respete. En los sitios donde los recursos son escasos y falta la aprobación del mundo exterior, el honor social es frágil, necesita afirmarse día a día (Sennett, 2009, p. 47).

Es esta falta de respeto el que pudo originar la muerte, ocasionarla, y es también el que se denuncia en la obscena mostración de los cuerpos de las mujeres. Pues un cadáver exhibido no es un cuerpo respetado. Los cadáveres de las mujeres operan como permanente denuncia de una masculinidad vulnerada que necesita matar para recuperar un honor inexistente pero reclamado. Un honor anulado por los procesos estructurales de una violencia socioeconómica y de dinámicas culturales irreversibles expresadas en las diferencias de género, de clase, de etnia, religiosas y generacionales de que Bolaño va dando cuenta en la ciudad de Santa Teresa y en cada uno de los escenarios del crimen.

4 Injusticia, sinsentido, irracionalidad

Varios giros operan en los escenarios y en las tramas propias de la novela negra. En la novela contemporánea, la figura del detective y del 
policía se funden: el detective es un policía. Mientras Salvo Montalbano - detective y policía - es actor y protagonista principal en Camilleri, así como Wallander en Mankell, este rol se torna en un conjunto de personajes difusos en Bolaño, mostrando la realidad de una policía latinoamericana inoperante e ineficaz.

Pedro Negrete - el detective de La parte de los crímenes - no está movido por un sentimiento de justicia y la distancia resulta de un relato en que su secuencia personal, su vida cotidiana y sus raciocinios no son la base narrativa de la novela. No obstante, encontramos la operación del diálogo, la reflexión y el aprendizaje del oficio y se reproducen secuencias en que los "ayudantes" del detective o comisario principal realizan intercambios que permiten resaltar los rasgos fundamentales del personaje. Enfrentando las debilidades humanas de la sociedad y de sus ayudantes, Lalo Cura, el joven policía de 2666, será entrenado y aprenderá la realidad del delito, del trabajo policial y de la investigación.

El hilo conductor, la racionalidad de una esfera tal vez trascendente a toda novela policial es giro aleatorio en la novela negra. Un comisario con quien comienza y termina la novela, cuyo hilo de deducciones, peripecias, esfuerzos, emociones y cotidianeidad, en Camilleri, ordena la narrativa, contrasta con una violencia que se despliega a modo de crónica roja, a fuerza de anuncios y siguiendo el hilo del paso del tiempo en Bolaño.

Inevitablemente, la violencia contra las mujeres de México - violencia sexual, violencia del cuerpo - muestra la dimensión política del drama: la policía no da cuenta, los crímenes no se resuelven, no se encuentran secuencias tampoco. Múltiples conflictos estructurales se van desplegando, mostrando una realidad en que el Estado está imposibilitado de proteger a la sociedad. Una sociedad que convive con la naturalidad de del homicidio, del machismo violento y de la desprotección. La policía, curiosa de resolver, actúa a la par que la prensa, pautada por ella. La violencia doméstica, la 
violencia socioeconómica, el tráfico de drogas, la pornografía se conjugan en un mundo cuya dinámica da vida a la prensa y la policía, sin que estas puedan realizar el cometido de proteger a la comunidad, sino que la lógica profesional -la razón moderna de Adorno y Horkheimer - se plasme en la concreción de una justicia global o al menos parcial.

La justicia no llega para las mujeres muertas, que son cadáveres sin historia. Algunas reclusiones y apresamientos operan y la trama ya no es la de la lógica y secuencia de una razón que se despliega so pretexto de la psiquis, lógica y razón de un narrador principal -detective o policía. La prensa y su dinámica - con esa cotidianeidad volátil - escenifica una violencia en que las muertes, de principio a fin, dan la trama de los espacios en que se van produciendo. La violencia de México - en la novela de Bolaño - radicaliza la distancia con la "salvación", en tanto la destrucción que campea en el mundo no se opone, sino que se refleja en el detective principal (y ello, con mayor claridad, si lo oponemos a los elementos racionales y estructurados que un relato guiado como el de Camilleri ofrece). Se refuerza la pérdida de esperanza que la impunidad y las dinámicas de la violencia social recrudecen en América Latina.

La violencia consuetudinaria se despliega en el texto de Bolaño con cuenta gotas, las esperanzas son tan vanas al inicio como al final y las preguntas que se van articulando y dando cuenta de la violencia social y de Estado en México van anunciando un contexto en el que la justicia no llega: los casos concretos quedan sin resolver, eje clave que permite a la novela policial reproducir su lógica ad infinitum. Solo queda claro que una violencia desatada por hombres, que al inicio figuran como psicópatas, a veces tomados por la furia, a veces por el odio y que cíclicamente atentan contra mujeres de diferente edad, va dando un giro hacia una violencia estructural vinculada a la pornografía, bajo sus formas más truculentas, que emerge en una sociedad marcada por el machismo, el narcotráfico y 
la explotación económica y quita todo valor a la vida humana. La obscenidad del relato de las muertes da cuenta de la obscenidad de un mundo que no se deja esclarecer (tal como lo requiere el romance policial para ser tal) aunque nos arroja a la cara hilos, pistas, detalles que nadie atará.

Esta secuencia "del hecho" no es más la secuencia de una novela en que la figura del detective - policía o no - está para recordar que en algún plano de la vida cotidiana la astucia, la deducción y las percepciones ponen en contacto el mundo de la esfera cotidiana con un trascendente salvador, con principios generales de justicia o con la comprensión de un mundo oscuro e incomprensible en que los personajes se conectan intersubjetivamente sin una secuencia de acciones humanas que permita algún desenlace.

Los criminales desfilan de todo tipo y color - violadores, profanadores de iglesias (el penitente), hospitales psiquiátricos, cárceles, policías y policías corruptos, mercenarios, empresarios y poderosos locales - sin que la pregunta guía de Henning Mankell o Andrea Camilleri aparezca: ¿hacia dónde va Suecia? se pregunta con angustia Kurt Wallander. ¿Qué ocurre en Italia? intenta saber un Montalbano indignado por cada una de las tramas que los crímenes que procura establecer le traen. Vivimos en Bolaño una circularidad del presente en que las formas más cruentas de la violencia horrorizan por su forma, pero se naturalizan como dato de la realidad. El sustrato ideológico que la narración denuncia es el individualismo excesivo, la descolectivización, la desprotección y la falta de humanismo, ya no como expresión de un particular punto de vista en una circunstancia concreta, sino como trasfondo de la sociedad mexicana.

En Italia, en Suecia, nos confrontamos a un país que cambia, un horizonte que se pierde, historias que no son creíbles para un imaginario en que la justicia era aún posible y la sociedad se torna un escenario de conflictos en que la policía trabaja denodadamente para resolver los casos. Pero existe, en una policía sistemática y ordenada (Mankell) o pa- 
sional pero obediente (Camilleri), la figura de detectives sensibles y comprometidos, como contracara de un mundo en fuga. Aun así, en Suecia y en Italia, la lógica de la deducción, el trabajo en equipo, la aventura y la acción se complementan con el esclarecimiento del caso. Si bien la realidad se muestra, día a día, menos predecible para Salvo Montalbano y Kurt Wallander en tanto detectives y cada caso es testimonio de un conflicto social mayor (de la desestructura de un mundo integrado en Suecia o de la persistencia de redes ilegales, del tráfico de personas, de delitos menores, de corrupciones locales en Italia), aun así podemos tener al fin del relato la "comprensión" de lo ocurrido, propio del romance policial.

\section{Nuda vida}

De cada víctima que aparece en La parte de las muertes se brindan detalles de forma sistemática: la edad, la estatura, el oficio, la ropa que llevaba puesta, el nombre y la causa de la muerte. Aunque la mayoría de los asesinatos se ajustan a un mismo patrón, otros difieren ${ }^{3}$. El hilo conductor se produce a golpe de estas noticias y ya no tiene al investigador como eje. Si antes el detective emprendía la actividad guiada por la razón, aquí la prensa exhibe día a día la realidad seriada de las muertes de mujeres de las que se sospechan causas, conexiones, pero nunca se llega a una resolución, resolución que anticipa aún la posibilidad de la justicia, por vía de la ley que

\footnotetext{
${ }^{3}$ Entre las descripciones de los crímenes se intercalan historias paralelas. Una de ellas es la investigación que lleva a cabo sobre el caso el policía Juan de Dios Martínez y su relación con Elvira Campos, la directora de manicomio de Santa Teresa. Sus investigaciones incluyen la búsqueda de un profanador de iglesias descontrolado que ha cometido homicidios. Otra historia es la de Klaus Haas, llevado a prisión a consecuencia de las investigaciones llevadas a cabo por el agente Epifanio por considerarlo el autor de los asesinatos de Santa Teresa. También encontramos la historia de la adivina que interviene en un programa de televisión para pedir que se resuelvan los casos o la de una diputada del PRI que, tras la desaparición de su amiga, le encomienda a un periodista la investigación del caso.
} 
la encarna en la esfera terrenal. No existe la insaciabilidad del aventurero y su esperanza o desilusión (como Salvo Montalbano).

Desaparece el héroe que era el detective en la novela policial que describe Kracauer (2011). Aquel que no podía morir porque la "razón" sin fin debía comportarse heroicamente. Si llegara a morir su muerte sería contingente, no una prueba final. Los rasgos heroicos coinciden con la característica de quiénes han sido arrebatados al destino (el que sí tienen las muertas que nadie salva), engendros de la intención de hacer visible en la realidad todas las contrapartes de la figura. Desaparece en la novela negra el detective que tiene el poder del hechizo y las actitudes del maestro. Aunque prosiguen los casos aislados que se topan con agentes de la policía, estos no son héroes, ni creen en la racionalidad del método.

Cuando Epifanio le preguntó por qué razón había ido al barranco de Podestá, Lalo cura le contestó que porque era policía. Usted es un escuincle de mierda, le dijo Epifanio, no se meta donde no le llaman, buey. Después Epifanio lo cogió de un brazo y lo miró a la cara y le dijo que quería saber la verdad. Me pareció raro, dijo Lalo Cura, en todo este tiempo nunca había aparecido una muerta en el barranco de Podestá. ¿YY eso usted cómo lo sabe, buey? Dijo Epifanio. Porque leo los periódicos dijo Lalo Cura. ¿Y también lee libros, supongo? Pues sí, dijo Lalo Cura. ¿Los putos libros para putos que yo le regalé? Los Métodos modernos de investigación policiaca, del ex director en jefe del Instituto Nacional de Policía Técnica de Suecia, el señor Harry Söderman y del ex presidente de la Asociación Internacional de Jefes de Policía, el ex inspector John J. O'Connell, dijo Lalo cura. ¿Y si esos mentados superpolicías eran tan buenos por qué ahora son unos putos ex?, dijo Epifanio. ¿A ver, contésteme ésa, buey? ¿No sabe usted, pendejete, que en la investigación policiaca no existen los métodos modernos? Usted todavía ni ha cumplido los veinte años, ¿me equivoсо? No te equivocas, Epifanio, dijo Lalo Cura. Pues ándese con cuidado, valedor, ésa es la primera y la única norma, dijo Epifanio soltándolo del brazo y sonriendo y dándole un 
abrazo y llevándoselo a comer al único lugar donde servían pozole en el centro de Santa Teresa, en esas horas turbias de la noche (Bolaño, p. 658).

Estas voces nos dejan sin esperanzas. El policía pasa a ser un personaje más que lucha por su sobrevivencia en un mundo en que la conciencia de su inoperancia contrasta con la valentía de las aventuras de los detectives-policías de la Europa Latina o Sajona. Y esto también es expresión de su realidad estructural. El arraigo histórico de la violencia institucional en la policía colide a veces con la falta de método policial y el respeto de la legalidad y se expresa en la descreencia que el mismo que Epifanio representa.

Pues el disciplinamiento, como "nueva forma de obediencia" y de control social que permitió la regulación y el manejo de poblaciones, se caracteriza como nueva forma de poder de la modernidad por ser individualizante y totalizadora: el colectivo que se quiebra para reorganizarse en unidades más eficientes no deja de ser, aún así, un colectivo. Para llevar adelante esta tarea, el poder se transforma en saber y el saber en poder. La soberanía del monarca es sustituida por la disciplina de la ciencia, y la ley de la tradición por la última ley de conducta encontrada, paradigma de toda policía y método moderno (Foucault, 1976).

Ello supone que las nuevas formas de disciplina no están asociadas a dueños individuales, sino que se transforman en parte asumida del orden natural. Con la transición de la coerción a la terapéutica, el interés de la autoridad incita la buena conducta y sustituye el tratamiento coercitivo con vistas a la optimización. El descubrimiento de estas formas de poder en la policía supone también el uso de la investigación, el método y la racionalidad para resolver el crimen. Sin embargo, nada más lejos de esta realidad que la figura del policía latinoamericano tradicional (Centeno, 1988).

Lejos estamos de aquel detective entendido como un neutrum, ni erótico ni puramente espiritual, sino como un "Ello" que no alcanza a 
verse afectado, cuya objetividad se explica a partir de un intelecto en el que nada puede influir porque se basa en la nada al decir de Kracauer (2010, p. 84). Esta figura cambia, trastocada en parte por la fusión con la figura del detective que tradicionalmente actuaba tanto con como contra policías y criminales. Esta duplicidad del policía detective se hace virtud en Camilleri y Mankell, atraso social en Bolaño. No son los héroes de la sociedad racionalizada que podían resolver crímenes y actuar en una comunidad dañada que reparar. La relación deja de ser aquella fluctuante del detective con la policía (individuo y sociedad) para pasar a ser la de la propia policía contra el hombre, una policía atrasada, corrupta y medrosa en una sociedad vulnerada.

No es este el lugar de quienes han incorporado lo humano; el sentimentalismo en la novela policial es un cotejar anticipado de la meta. La ratio, que siempre saca todo a la luz, consuela el sentir perdido: al establecerse la incuestionable relación de inmanencia se mostrará simultáneamente el final. El final -que en verdad no lo es, ya que sólo pone fin a la irrealidad- evoca el sentimiento, que es irreal, y finalmente se introducen soluciones, que no lo son, para obligar al cielo, que no existe a bajar a la tierra. Así lo kitsch delata al pensamiento despojado de realidad, que reviste la apariencia de las esferas supremas (Kracauer, 2010, p. 168).

Tensando el abismo entre la razón y la ley, en que la distancia con la ley es recrudecida por la pérdida de sentido que la posibilidad del acto mágico de la racionalidad y la comprensión tal vez permitiría acortar, la violencia social se suma a la denuncia de una institucionalidad cuyas prácticas se orientan por la defensa personal, corporativa y la relación corrupta con un orden social que no puede transformarse. La autonomía de que goza la policía cuando actúa como órgano del Estado está basada también en la creencia "burocrático-legal" de la ley y de los procedimientos a seguir en los casos indicados. Esto es, en la creencia en los Derechos Humanos y en la legalidad de las prácticas institucionales. 
Su efectividad (en que se basa el ideal de "protección" que la ciudadanía reclama) está orientada entre otras cosas a la prevención de acontecimientos y actos posibles teniendo en cuenta todas las circunstancias especiales de la vida, que en razón de su permanente y cambiante multiplicidad no pueden definirse de antemano. En la novela negra, la policía aparece diluida con otros actores, está atrás del hecho, busca series de acontecimientos que puedan enlazarse y comprenderse, pero no es más que otro actor en la trama. Acontecimiento, materialidad infinita, desprotección, violencia consuetudinaria, realidad inasible son otros tantos elementos que tanto afectan el cotidiano social como denuncian la vulnerabilidad reinante de que la misma institución policial está presa.

En el género policial, como defensora de lo legal, la policía asume una posición cuya legitimidad no deriva de una fuente superior del derecho sino del vínculo con la misma sociedad y su territorio. En Bolaño, el pueblo y los individuos a que está dedicada la institución, la comunidad, pasan a ser un "coexistir" de figuras privadas de vínculo entre ellas. Los escenarios de la novela siguen el hilo de la prensa en Bolaño: una cotidianeidad sinfín, aleatoria, pautada por el poder de los medios de comunicación, que pierde valor y contrasta con la novela cuyo destino es permanecer.

Al finalizar el año 1996, se publicó o se dijo que en algunos medios mexicanos que en el norte se filmaban películas con asesinatos reales, snuff-movies, y que la capital del snuff era Santa Teresa. Una noche dos periodistas embozados hablaron con el general Humberto Paredes, antiguo jefe de la policía del DF, en su castillo amurallado de la colonia del Valle. Los periodistas eran el viejo Macario López Santos, un comillo de la nota roja desde hacía más de cuarenta años, y Sergio González (p. 669).

Cuando se encuentra la última muerta en el año 1997 cierra el capítulo: Tanto este caso como en el anterior fueron cerrados al cabo de tres días de investigaciones más bien desganadas. Las 
navidades en Santa Teresa se celebraron de la forma usual. Se hicieron posadas, se rompieron piñatas, se bebió tequila y cerveza. Hasta en las calles más humildes se oía a la gente reír. Algunas de estas calles eran totalmente oscuras, similares a agujeros negros, y las risas que salían de no se sabe dónde eran la única señal, la única información que tenían los vecinos y los extraños para no perderse (Bolaño, p. 973).

La realidad de que denuncia la nuda vida (Agamben, 1998) en La parte de los muertos se despliega en la obscenidad de la muerte que acaece una y otra vez. Una comunidad herida se subsume en el rito de la fiesta tradicional que toma el espacio público. En ella, estos agujeros negros, las muertes, no serán resueltos: no se recompondrá el lazo social. Permanecen como eco las risas de los muertos en un territorio desmembrado.

Ese sentimiento que debía unir a una comunidad para ser más que difusa sociedad (Weber 1992), emerge en la fiesta que permite escenificar el dolor de los habitantes de Santa Teresa. Heridos por las muertes, la búsqueda de la verdad no desaparece en Bolaño. La magia de la "racionalidad" del detective héroe sería del orden de la recomposición que la novela pretende aún en la denuncia de un orden social.

Bolaño, en su obra literaria, nos muestras así un camino surcado de horrores en la realidad mexicana $-y$, por qué no, occidental - respecto de la preservación de la vida y del rol del Estado en el proceso que debería llevar al logro a los derechos individuales y el progreso social. La novela respondería, a la pregunta de Agamben respecto del sentido de este proceso, que estos horrores no son accidentales sino inherentes a nuestro proceso. El detalle dado sobre cada una de las muertas (oficio, peso, estatura, edad, ropa) muestran al hombre no como sujeto sino como cuerpo vivo, un cuerpo surcado por la violencia de un Estado que es Estado de Excepción por regla. 


\section{Estilo y realidad}

2666 de Bolaño es la novela negra de la realidad latinoamericana: horizontes sin esperanzas frente a una violencia estructural e histórica que se transmuta en una contemporaneidad tan cruel como actualizada en las redes globales que vinculan México con Norteamérica y encuentran sus raíces en una sociedad que sufre la dependencia, la pobreza y la exclusión. Esta "carne de cañón", esta secuencia de mujeres muertas, va desvendando en los hechos - no en la lógica del detective propia de la novela policial - una estructura histórica del delito que la policía va contornando sin poder adentrarse, en conjunto con otros personajes: la prensa nacional y regional, los responsables de instituciones psiquiátricas, la iglesia, la cárcel, la comunidad y el vecindario.

Hemos propuesto que puede establecerse una relación entre el estilo que la novela negra tiene en Bolaño y el tipo de violencia criminal y homicida que es relatada en el escenario latinoamericano. Sin zanjar el debate propio de la Escuela de Frankfurt, respecto del vínculo entre novela policial o novela negra y obra de arte, entendemos que la novela negra permite algunos elementos esenciales propios del poder liberador de todo producto artístico. En parte habilita a la comprensión de la realidad que muestra - más allá de que el "esclarecimiento" propio de la novela policial no esté presente -, a la vez que permite el ejercicio crítico y la denuncia de la realidad social propia de una contemporaneidad violenta, injusta y desigual. Su poder está en la deconstrucción de las nociones y categorías que pone en juego un determinado código hermenéutico como constructo teórico en una narración en que los acontecimientos cronológicos están focalizados por la ideología. Una ideología que, en la novela policial, sugiere de la forma ideológica del esclarecimiento y la justicia como concreción de racionalidad e ideal civilizatorio. 
Esta crítica desnuda diferentes aspectos que estructuran el mapa social de una contemporaneidad en que la modernidad radical se despliega sin progreso social. La violencia institucional de la policía hace a la necesidad de que retroceda la tradicional figura del detective-policía que estructura la novela policial. Presente en la obra, la policía de Bolaño descree de la racionalidad y del método y convive en un mundo en que la justicia difícilmente se materializa y la creencia en la institucionalidad del Estado y en la legalidad de las reglas es escasa.

La secuencia de las muertes también es denunciada como violencia consuetudinaria y naturalizada en la narrativa del texto que se estructura a golpe de notas de prensa. Las mismas atestiguan de la multiplicidad y continuidad de estas violencias - criminales, urbanas, homicidas - a la vez que de la escasa trascendencia e importancia del valor de la vida humana. Tienen el valor de una nota de prensa: pasajera, fugaz. El terreno de la impunidad abona así un mapa social en que campean diferentes expresiones de violencia excesiva y egoísta, en que la pornografía y el machismo se tornan expresiones extremas del tipo de crímenes de que son víctimas las mujeres.

El hallazgo de los cuerpos tirados, abandonados, una muerte "no esperada" que sigue los rituales del horror en tanto crónica de la violencia consuetudinaria en un mundo que radicaliza la violencia como forma de dominación. La obra despliega los cuerpos muertos de mujeres en una expresión simbólica que desnuda el conflicto social por vía de su narración. La obscenidad del espectáculo reiterado de las muertes hace de la novela en sí un intento de saldar el gesto incompleto que la realidad deja abierta.

No hay astucia posible que permita salvar a esta humanidad. Ni la de Odiseo en la Ilíada (Horkheimer, Adorno, 1998) anticipando la razón moderna contra las trampas de un mundo tradicional, ni la del método científico en un detective policía que desvenda los hilos de un psicópata 
cuyo apartamiento del mundo permitirá que la "normalidad" vuelva a su cauce. La normalidad recorre otros parámetros en los cuales los cursos de acción de los individuos que infringen violentan y matan son el producto de una sociedad fragmentada y vulnerable en que la acumulación de la violencia social explica la valorización del uso de la fuerza como exceso de poder en escenarios carentes de reconocimiento y prestigio social.

Los cadáveres de las mujeres testimonian así de cursos regulares de la violencia social en México: la violencia de género y la masculinidad exacerbada, la explotación económica y sexual, el tráfico de drogas, la violencia simbólica en la mostración de los cuerpos, la violencia institucional a través de la policía. La complejidad de las formas de la violencia y de sus significados culturales y sociales que retrata la obra literaria permite a la sociología ampliar su objeto abordando de las lógicas culturales de nuestra conflictividad social contemporánea.

Nilia Viscardi. Docente e Investigadora en el Departamento de Sociología, Facultad de Ciencias Sociales y en el Departamento de Pedagogía, Política y Sociedad de la Facultad de Humanidades y Ciencias de la Educación, Universidad de la República, Uruguay.

$\sum$ nilia.viscardi@gmail.com

\section{Referências}

ADORNO, T.; HORKHEIMER, M. Dialéctica de la Ilustración. Fragmentos filosóficos, Madrid: Trotta, 1998.

AGAMBEN, G. Homo sacer. El poder soberano y la nuda vida. Valencia: PreTextos, 1998.

ARIÈS, P. La muerte en Occidente. Barcelona: Argos Vergara, 1982.

BECKER, H. Métodos de pesquisa em Ciências Sociais. São Paulo: Hucitec, 1997.

BECKER, H. Outsiders. Hacia una sociología de la desviación. Buenos Aires: Siglo Veintiuno, 2010. 
BOLAÑO, R. 2666. Barcelona: Anagrama, 2011.

BOURDIEU, P.; WACQUANT, L. Respuestas. Por una antropología reflexiva. México: Grijalbo, 1995.

BOURGOIS, P. Más allá de una pornografía de la violencia. In: FERRÁNDIZ, F.; FEIXA, C. (eds). Jóvenes sin tregua. Culturas y políticas de la violencia. Barcelona: Anthropos, 2005, p. 11-34.

CAMILLERI, A. Un giro decisivo. Barcelona: Salamandra, 2004.

CAMILLERI, A. El miedo de Montalbano. Barcelona: Salamandra, 2007.

CASTEL, R. La inseguridad social. ¿qué es estar protegido?. Buenos Aires: Manantial, 2007.

CENTENO, M. A. "The disciplinary Society in Latin America", Draft paper presented at the Conference "The other mirror: Comparative History and Latina America", Program in Latin American Studies, Princeton University, February, 1998.

DURKHEIM, E. Las reglas del método sociológico. Madrid: Alianza, 1988.

ELÍAS, N. El proceso de la civilización. México, DF: Fundación de cultura económica, 2011.

ESTÉBANEZ CALDERÓN, D. Diccionario de términos literarios. Madrid: Alianza, 1996.

FOUCAULT, M. Genealogía del Racismo. Buenos Aires: Altamira, 1996.

FOUCAULT, M. Seguridad, territorio y Población. México: Fondo de Cultura Económica, 2006.

HENNING, M. La leona blanca. Buenos Aires: Tusquets editores, 2003.

HENNING, M. La falsa pista. Buenos Aires: Tusquets editores, 2009.

JAMESON, F. Documentos de cultura, documentos de barbarie: La narrativa como acto socialmente simbólico. Madrid: Visor, 1989.

KESSLER, G. Sociología del delito amateur. Buenos Aires: Paidós, 2004.

KESSLER, G. El sentimiento de inseguridad. Buenos Aires: Siglo Veintiuno, 2009.

KRACAUER, S. La novela policial. Un tratado filosófico. Buenos Aires: Paidós, 2010.

LE BLANC, G. Vidas ordinarias, vidas precarias. Sobre la exclusión social. Buenos Aires: Nueva Visión, 2007.

MISSE, M. Violência, crime e corrupção: conceitos exíguos, objeto pleno. In: TAVARES DOS SANTOS, J. V.; TEIXEIRA, A. N. Conflitos sociais e perspectivas da paz. Porto Alegre: Tomo Editorial, 2012. p. 25-42. 
PITA, M. V. Formas de morir y formas de vivir. El activismo contra la violencia policial. Buenos Aires: CELS, Del Puerto, 2010.

SENNETT, R. El respeto. Sobre la dignidad del hombre en un mundo de desigualdad. Buenos Aires: Anagrama, 2009.

TAVARES DE SANTOS, J. V. Violências e conflitualidades. Porto Alegre: Tomo editorial, 2009.

WEBER, M. Economía y sociedad. Esbozo de sociología comprensiva. Madrid: Fondo de Cultura Económica, 1992.

Recebido em: 23/05/2013

Aceite final: 20/08/2013 